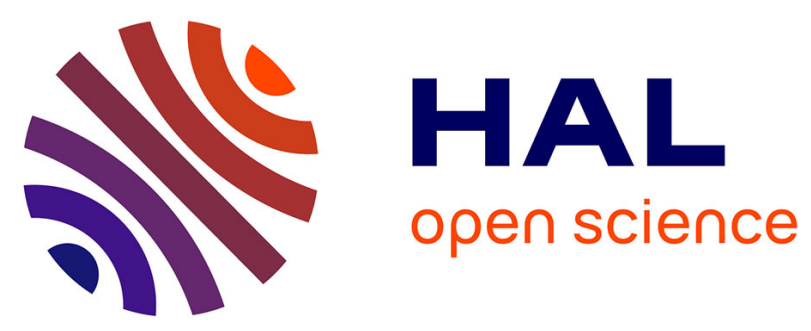

\title{
Synthesis of Cs-ABW nanozeolite in organotemplate-free system
}

Tamara Mahmoud Ali Ghrear, Séverinne Rigolet, T. Jean Daou, Svetlana Mintova, Tau Chuan Ling, Soon Huat Tan, Eng-Poh Ng

\section{- To cite this version:}

Tamara Mahmoud Ali Ghrear, Séverinne Rigolet, T. Jean Daou, Svetlana Mintova, Tau Chuan Ling, et al.. Synthesis of Cs-ABW nanozeolite in organotemplate-free system. Microporous and Mesoporous Materials, 2019, 277, pp.78-83. 10.1016/j.micromeso.2018.10.014 . hal-02047590

\section{HAL Id: hal-02047590}

\section{https://hal-normandie-univ.archives-ouvertes.fr/hal-02047590}

Submitted on 26 Nov 2020

HAL is a multi-disciplinary open access archive for the deposit and dissemination of scientific research documents, whether they are published or not. The documents may come from teaching and research institutions in France or abroad, or from public or private research centers.
L'archive ouverte pluridisciplinaire HAL, est destinée au dépôt et à la diffusion de documents scientifiques de niveau recherche, publiés ou non, émanant des établissements d'enseignement et de recherche français ou étrangers, des laboratoires publics ou privés. 


\title{
Synthesis of Cs-ABW Nanozeolite in Organotemplate-free System
}

Tamara Mahmoud Ali Ghrear, ${ }^{\mathrm{a}}$ Severinne Rigolet, ${ }^{\mathrm{b}}$ T. Jean Daou, ${ }^{\mathrm{b}}$ Svetlana Mintova, ${ }^{\mathrm{c}}$ Tau Chuan Ling, ${ }^{\mathrm{d}}$ Soon Huat Tan, ${ }^{\mathrm{e}}$ Eng-Poh Nga,

${ }^{a}$ School of Chemical Sciences, Universiti Sains Malaysia, 11800 USM, Penang, Malaysia.

${ }^{b}$ Université de Haute-Alsace, Université de Strasbourg, Axe Matériaux à Porosités Contrôlées, Institut de Science de Matériaux de Mulhouse UMR 7361, ENSCMu, $3 b$ rue Alfred Werner, 68093 Mulhouse, France.

${ }^{c}$ Laboratoire Catalyse \& Spectrochimie, ENSICAEN, Université de Caen, 14000 Caen, France. ${ }^{d}$ Institute of Biological Sciences, Faculty of Science, University of Malaya, 50603 Kuala Lumpur, Malaysia.

${ }^{e}$ School of Chemical Engineering, Engineering Campus, Universiti Sains Malaysia, Penang, Malaysia

*Corresponding author. Tel: +6046533550; e-mail address: epng@usm.my

\begin{abstract}
:
Cesium-aluminosilicate zeolite nanocrystals with $\mathrm{ABW}$ framework structure are synthesized free of organic template using hydrothermal approach. The crystallization process of Cs-ABW zeolite nanocrystals by varying the initial gel molar composition, heating temperature and crystallization time was studied. More detailed investigations of the formation of Cs-ABW nanozeolite using a reactive clear precursor hydrogel $\left(4 \mathrm{SiO}_{2}: 1 \mathrm{Al}_{2} \mathrm{O}_{3}: 16 \mathrm{Cs}_{2} \mathrm{O}: 160 \mathrm{H}_{2} \mathrm{O}\right)$ were then carried out. Fully crystalline Cs-ABW nanozeolites were obtained within 120 min at 180 ${ }^{\circ} \mathrm{C}$ and 22 bar, which is considerably faster in comparison to the currently available method involving treatment at $695^{\circ} \mathrm{C}, 1000$ bar and $46 \mathrm{~h}$. The $\mathrm{Cs}-\mathrm{ABW}$ nanocrystals have grain shape morphology with a mean size of $32 \mathrm{~nm}$ and they do not agglomerate for long durations. The nanosized $\mathrm{Cs}-\mathrm{ABW}$ zeolite has high alumina content $(\mathrm{Si} / \mathrm{Al}$ ratio $=1.04)$. These nanocrystals
\end{abstract}


can be prepared in high solid yield (ca. 82\%) thus offering a promising route for large-scale production of highly basic zeolite nanoparticles.

Keywords: Cs-ABW; Zeolite nanocrystals; Nucleation; Crystal growth; Template-free synthesis; Fast hydrothermal synthesis

\section{Introduction}

Zeolites are crystalline microporous aluminosilicates made from $\left[\mathrm{AlO}_{4}\right]^{3-}$ and $\left[\mathrm{SiO}_{4}\right]^{4-}$ tetrahedral units, forming channels and cavities. Zeolites are widely used in catalysis, ion exchange, adsorption and separation processes due to their high porosity, tunable acidity/basicity and high ion-exchange capacity [1-3]. Recently, a number of works has been reported on the synthesis, characterization and applications of zeolites with crystallite size below $100 \mathrm{~nm}$ due to their superior properties such as reducing diffusion path length, large external surface area, high colloidal stability, etc. [4-7].

Typically, zeolite nanocrystals are synthesized using organic templates (amine, imidazolium or quaternary ammonium salts) for controlling the crystallite size [8-10]. In addition, other more eco-friendly and cheaper approaches such as seed-induced [11, 12], ionothermal [13], post-milling recrystallization [14, 15], confined space synthesis [16] and organotemplate-free $[17,18]$ methods were used to prepare nanosized zeolite and zeotype materials. So far, a number of zeolite nanocrystals (*BEA [19], EDI [5], EMT [20], FAU [21, 22], GIS [23], LTA [24], LTJ [17], LTL [25], MEL [26], MER [27], MFI [28], MOR [29], SOD [30]) and zeotype (AEI [31], AFI [32], AFO [33], CHA [34]) has been successfully synthesized. 
The zeolite of ABW topology with a framework composition of $\mathrm{LiAlSiO}_{4} \cdot 2 \mathrm{H}_{2} \mathrm{O}$ was first synthesized by Barrer and White in 1951 [35]. The ABW framework is constructed by 4-, 6- and 8-rings of $\mathrm{TO}_{4}$ tetrahedral $(\mathrm{T}=\mathrm{Si}, \mathrm{Al})$, forming one-dimensional 8-membered ring $(8 \mathrm{MR})$ channel system (diameter of $3.4 \times 3.8 \AA^{2}$ ) [36]. Typically, ABW framework is preferentially formed in the hydrogels containing $\mathrm{Li}^{+}$cations $\left(250{ }^{\circ} \mathrm{C}, 72 \mathrm{~h}\right)$ [37]. Furthermore, the formation of ABW zeolite templated by $\mathrm{Cs}^{+}$cation was also reported in 1970s (700-1200 ${ }^{\circ} \mathrm{C},>1000 \mathrm{bar}, 46 \mathrm{~h}$ ) [38]. The synthesis condition of Cs-ABW has recently been improved to a much lower temperature and pressure $\left(695^{\circ} \mathrm{C}, 1000\right.$ bar) but the crystallization time was the same [39, 40]. As described, the synthesis of ABW-type zeolite still requires long crystallization time, extremely high temperature and pressure. Thus, ABW-type zeolites are rarely reported considering its tedious and dangerous synthesis condition. Also, nucleation and crystal growth of nanosized Cs-ABW zeolite has also not been reported so far and hence, it is the basis of this study.

In this work, Cs-ABW zeolite nanocrystals synthesized in template-free $\mathrm{Al}_{2} \mathrm{O}_{3}-\mathrm{SiO}_{2}-$ $\mathrm{Cs}_{2} \mathrm{O}-\mathrm{H}_{2} \mathrm{O}$ precursor system are reported. The effects of zeolite synthesis parameters including initial molar composition of precursor mixture, temperature and crystallization time are firstly studied. Secondly, the crystal growth process of the ABW nanocrystals are studied in timedependent experiment under mild and safe synthesis conditions (low temperature and pressure) compared to the previous works. The crystallization process of Cs-ABW nanocrystals is monitored using microscopic and spectroscopic methods.

\section{Experimental}

\subsection{Hydrothermal synthesis of nanosized Cs-ABW zeolite}


The nanosized Cs-ABW was prepared as follows: Firstly, clear aluminate solution was prepared by dissolving CsOH. $\mathrm{H}_{2} \mathrm{O}$ (3.500 g, Sigma-Aldrich) and $\mathrm{Al}(\mathrm{OH})_{3}(0.414 \mathrm{~g}$, Acros) in distilled water $\left(2.688 \mathrm{~g}\right.$ ) at $105{ }^{\circ} \mathrm{C}$ for $16 \mathrm{~h}$ under continuous stirring (400 rpm). Next, a clear silicate solution was obtained by mixing HS-40 (1.594 g, Sigma-Aldrich) and $\mathrm{CsOH}_{2} \mathrm{H}_{2} \mathrm{O}$ $(10.763 \mathrm{~g})$ in distilled water $(2.663 \mathrm{~g})$ at room temperature for $10 \mathrm{~min}$ under stirring $(400 \mathrm{rpm})$. The aluminate solution was then added slowly into the silicate solution under vigorous stirring (600 rpm) to obtain a clear precursor solution. The precursor sol with a molar composition of $4 \mathrm{SiO}_{2}: 1 \mathrm{Al}_{2} \mathrm{O}_{3}: 16 \mathrm{Cs}_{2} \mathrm{O}: 164 \mathrm{H}_{2} \mathrm{O}$ was stirred for another $5 \mathrm{~min}$ before transferring into a $15-\mathrm{mL}$ Teflon autoclave for crystallization at $180{ }^{\circ} \mathrm{C}(10,17,30,60$ and $120 \mathrm{~min})$. To ensure high reproducibility of the synthesis, the mass of autoclave before and after heating was recorded; negligible amount of water $(<0.0020 \mathrm{~g})$ was lost from the samples after the heating. The suspension was purified with distilled water (centrifuged at $10000 \mathrm{rpm}, 15 \mathrm{~min}$ ) until $\mathrm{pH}$ of 8 was reached prior to freeze drying. All experiments performed via varying the chemical compositions of the precursor mixtures and synthesis conditions are summarized in Table 1.

\subsection{Characterization}

The crystallinity and purity of solids were investigated by a PANalytical X'Pert PRO diffractometer with $\mathrm{Cu}-\mathrm{K}_{\alpha}$ monochromatized radiation $(\lambda=1.5406 \AA)$. The measurement was performed with a scan speed of $0.2^{\circ} / \mathrm{min}$ and a step size of $0.02^{\circ}$. The degree of crystallinity was estimated by evaluating the intensity of the three most intense XRD peaks of the samples at $2 \theta$ of $27.5^{\circ}[202] /[112], 18.68^{\circ}[200] /[110]$ and $32.89^{\circ}[310] /[020]$, relative to the reference sample (Cs-ABW synthesized for $120 \mathrm{~min}$ ). The crystallite size of the zeolite nanocrystals was estimated by using the Scherrer equation. The morphological features and the crystal size of amorphous particles and zeolite nanocrystals were examined using a Philips CM12 TEM 
microscope operated at $200 \mathrm{kV}$. The particle size of the amorphous or crystal solids was measured by randomly counting of 50 particles through TEM images obtained in different areas. The infrared (IR) spectra of the solids were recorded with a Perkin Elmer spectrometer (System 2000) within the range of $1400-400 \mathrm{~cm}^{-1}$ using the $\mathrm{KBr}$ pellet technique (KBr:sample weight ratio $=50: 1)$

The chemical composition of samples was determined using a Varian Vista MPX ICPOES spectrometer (the solids were dissolved in a $\mathrm{HF}$ solution $(0.5 \mathrm{M}) ; \mathrm{H}_{3} \mathrm{BO}_{3}$ was then added into the prepared solution to avoid interferences of fluoride in the ICP-OES analysis). ${ }^{29} \mathrm{Si}(\mathrm{I}=$ 1/2) proton decoupled magic angle spinning (MAS + DEC) NMR spectra were recorded at room temperature with a Bruker Avance II $300 \mathrm{MHz}$ spectrometer operating at $\mathrm{B}_{0}=7.2 \mathrm{~T}$ (Larmor frequency $v_{0}=59.62 \mathrm{MHz}$ ) equipped of a Bruker $7 \mathrm{~mm}$ double channels probe. The probe rotor was spun at a spinning frequency of $4 \mathrm{kHz}$. Single pulse magic angel spinning (SPE-MAS) experiments were performed using a pulse angle of $\pi / 6(2.1 \mu \mathrm{s})$ and a recycling delay of $80 \mathrm{~s}$ under high-power proton decoupling conditions $(63 \mathrm{MHz})$. The chemical shifts were quoted relative to tetramethylsilane (TMS). The decompositions of the spectra were performed using the DMFit software $[41] .{ }^{27} \mathrm{Al}(\mathrm{I}=5 / 2)$ magic angle spinning (MAS) NMR was carried out with a Bruker Avance II 400 spectrometer operating at $\mathrm{B}_{0}=9.4 \mathrm{~T}$ (Larmor frequency $v_{0}=104.2 \mathrm{MHz}$ ) equipped with a Bruker $2.5 \mathrm{~mm}$ double channel probe. The rotor was spun at $25 \mathrm{kHz}$, and free induction decays (FID) were collected with a p/12 rf pulse (0.6 $\mathrm{ms}$ ) and a recycle delay of $1 \mathrm{~s}$. Measurements were carried out with $\left[\mathrm{Al}\left(\mathrm{H}_{2} \mathrm{O}\right)_{6}\right]^{3+}$ as an external standard reference.

\section{Results and discussion}

\subsection{Effect of synthesis parameters on the formation of $A B W$ nanosized zeolite}


The effects of the synthesis parameters such as the initial gel molar composition, heating temperature and crystallization time on the formation of $\mathrm{Cs}-\mathrm{ABW}$ crystals were first investigated (Table 1). Various amounts of $\mathrm{Cs}_{2} \mathrm{O}$ were used for the preparation of the initial mixture $\left(4 \mathrm{SiO}_{2}: 1 \mathrm{Al}_{2} \mathrm{O}_{3}: x \mathrm{Cs}_{2} \mathrm{O}: 164 \mathrm{H}_{2} \mathrm{O}\right)$, and then hydrothermal treatment was performed at $180{ }^{\circ} \mathrm{C}$ for $80 \mathrm{~min}$ (Table 1). It was found that the crystallization rate increased with increasing the $\mathrm{Cs}_{2} \mathrm{O}$ content, thus indicating the direct participation of soluble $\mathrm{Cs}_{2} \mathrm{O}$ species in crystal growth process. In addition, a reduction of crystallite size from $41 \mathrm{~nm}$ to $26 \mathrm{~nm}$ was observed with increasing the $\mathrm{Cs}_{2} \mathrm{O}$ molar ratio from 12 to 16 .

The influence of water content in the precursor mixture on the properties of the zeolites was studied as well. The XRD analysis revealed that all samples showed similar XRD patterns of ABW crystalline phase with slight different degree of amorphous matter present. Thus, it indicated that tuning water content had negligible effect on the purity of the crystalline phase but influenced the degree of crystallinity of the ABW zeolite. By the reducing water in the precursor mixture, the crystallite size decreased from $44 \mathrm{~nm}$ to $19 \mathrm{~nm}$. Such phenomenon happened because the precursor with reduced water content and higher alkalinity has higher solubility towards silicate and aluminate monomers. As a result, a high super-saturation solution for the formation of small nanocrystals, by which many nucleation sites can produce, was formed [42].

The effect of $\mathrm{SiO}_{2} / \mathrm{Al}_{2} \mathrm{O}_{3}$ ratio on the solid products formed was also studied. The XRD results showed that the crystallization rate was significantly affected by the silica content of the precursor mixture. When $\mathrm{SiO}_{2} / \mathrm{Al}_{2} \mathrm{O}_{3}$ ratios of 2 and 4 were used, Cs-ABW nanocrystals with crystallite sizes of $34 \mathrm{~nm}$ and $26 \mathrm{~nm}$ were obtained, respectively. Further increasing the $\mathrm{SiO}_{2} / \mathrm{Al}_{2} \mathrm{O}_{3}$ ratio to 6 , however, yielded amorphous solid as end product. 
In order to study the effect of $\mathrm{Cs}^{+}$cation in the formation of $\mathrm{ABW}$ framework, different types of metal hydroxide were used while the other synthesis parameters were constant $\left(4 \mathrm{SiO}_{2}: 1 \mathrm{Al}_{2} \mathrm{O}_{3}: 16 \mathrm{M}_{2} \mathrm{O}: 164 \mathrm{H}_{2} \mathrm{O}, \mathrm{M}=\mathrm{Na}, \mathrm{K}\right.$ or $\left.\mathrm{Cs}, 180{ }^{\circ} \mathrm{C}, 80 \mathrm{~min}\right)$. When $\mathrm{NaOH}$ and $\mathrm{KOH}$ were employed, the precursors did not yield ABW crystalline phase. Instead, CAN and LTJ framework structures were crystallized, respectively. Hence, $\mathrm{Cs}^{+}$plays an important role in governing the ABW phase selectivity during zeolite nucleation. The crystallite size of ABW zeolite $(26 \mathrm{~nm})$ was much smaller than LTJ $(94 \mathrm{~nm})$ and CAN (56 nm) zeolites. This phenomenon can be explained by the stronger alkalinity of $\mathrm{CsOH}$ than those of $\mathrm{KOH}$ and $\mathrm{NaOH}$ in enhancing the overall solubility of aluminate and silicate species promoting high super-saturation condition [43].

The precursor solution with a molar composition of $4 \mathrm{SiO}_{2}: 1 \mathrm{Al}_{2} \mathrm{O}_{3}: 16 \mathrm{Cs}_{2} \mathrm{O}: 164 \mathrm{H}_{2} \mathrm{O}$ were also subjected to heating at different temperatures $\left(140,160\right.$ and $\left.180{ }^{\circ} \mathrm{C}\right)$ for $80 \mathrm{~min}$ in order to study the effect of heating on the formation of Cs-ABW material. As shown, only the ABW crystalline solid product was obtained at $180{ }^{\circ} \mathrm{C}$ while the other two solids heated at lower temperatures were mostly amorphous indicating that the crystallization of Cs-ABW zeolite was a thermally-activated process. The effects of heating time was also studied and the formation of Cs-ABW zeolite was found to be time-dependent. The formation of Cs-ABW zeolite nanocrystals as a function of crystallization time will be discussed in the following sections.

\subsection{Kinetics of formation of Cs-ABW nanocrystals}

The synthesis of nanocrystalline Cs-ABW zeolite was prepared by mixing both the transparent aluminate and silicate solutions. The resulting clear suspensions became more viscous indicating the polymerization of aluminate and silicate species. The precursor was then 
subjected to hydrothermal treatment at $180{ }^{\circ} \mathrm{C}$ to induce further the crystallization. When this reactant sol was heated for $7 \mathrm{~min}$, the sol remained clear and no solid product was recovered at this stage. However, an increase in the solubility of the alumina and silica precursors was observed, which allowed more precursor species to dissolve in the sol and hence increasing the critical supersaturation of the sol. After $10 \mathrm{~min}$, the solution turned cloudy and a colloidal stable solution was obtained. The sample was separated and a soft gel was collected at the bottom of the centrifuge tubes. The mass of the solid product after purification and freeze drying was $28 \%$ (Fig. 1). According to the XRD analysis, this sample was an amorphous solid since no XRD diffraction peaks were detected and only a broad band at $2 \theta=27.2^{\circ}$ was observed (Fig. $2 \mathrm{a}$ and 3). Small particles with irregular shape and particle size of $16 \mathrm{~nm}$ were detected by TEM (Fig. 4a,b). With further heating of the suspension (17 min), semi-hard solid product embedded in hydrogel was recovered under centrifugation. The solid yield at this stage increased to $34 \%$ (Fig. 1). Furthermore, the XRD pattern of this sample contains an amorphous hump and several diffraction peaks at $2 \theta=18.80^{\circ}, 26.94^{\circ}, 27.52^{\circ}, 32.90^{\circ}$ and $38.78^{\circ}$, which corresponded to the (200)/(110), (211), (202)/(112), (310)/(020) and (312)/(022) planes of the ABW-type zeolite, respectively (Fig. 2b) [39]. The diffraction peaks were broad indicating the small crystallite size of zeolite domains. The degree of crystallinity of this solid sample was also determined (Fig. 3). It was shown that the amorphous entities were still dominated in the sample; $18 \%$ crystallinity was recorded. The XRD observation was supported by the TEM analysis. As shown in Fig. 4c,d, transformation of amorphous phase into the ABW zeolite nanocrystals was observed. The average crystal size of the ABW zeolite measured by TEM analysis is $17 \mathrm{~nm}$ and it was almost identical to that calculated from the Scherrer equation $(15.2 \mathrm{~nm})$.

The solid yield and the degree of crystallinity increased abruptly to $61 \%$ and $46.25 \%$, respectively when the precursor was further heated to 30 min (Figs. 1 and 3). All the diffraction peaks became more intense while very weak amorphous hump remained weak (Fig. 2c). As 
can be seen in the TEM images, the nanocrystals exhibited a grain shape which is different from that of Li-ABW micron-sized crystals (Fig. 4e,f) [44, 45]. Amorphous entity was still observed between the ABW nanocrystals. However, the amorphous solids slowly disappeared due to its consumption as a nutrient for the nucleation and crystal growth processes of zeolite nanocrystals. The particle size of the Cs-ABW nanocrystals was slightly increased to $25 \mathrm{~nm}$ (Scherer equation: $21 \mathrm{~nm}$ ).

The colloidal suspensions subjected to further hydrothermal treatment for 60 and $120 \mathrm{~min}$ were purified. At these crystallization stage, the solid yield further increased and maintained at about $82 \%$ (Fig. 1). The XRD pattern of sample heated for 60 min contains more intense Bragg peaks, which correspond to samples with $83 \%$ crystallinity (Fig. 2 d and 3). After 120 min, fully crystalline solid was obtained as indicated by XRD; the crystallite size of the ABW zeolite is about $28 \mathrm{~nm}$ (Fig. 2e). As shown, the XRD pattern of nanosized Cs-ABW zeolite is identical to that of Cs-ABW zeolite synthesized under high temperature and high pressure (Fig. 2f) [39]. The nanocrystals are well separated and the amorphous matter was transformed into Cs-ABW nanocrystals (32 nm, Fig. 4g,h). In comparison to the previous work (46 h) [38-40], the ABW nanocrystals were synthesized for shorter time thanks to the optimized precursor suspension used. In addition, the temperature $\left(180^{\circ} \mathrm{C}\right)$ and pressure (22 bar) used in the current study was much lower than those reported in the previous study $\left(695-1200{ }^{\circ} \mathrm{C},>1000\right.$ bar) [38-40].

Additionally spectroscopy techniques were used to follow the nucleation and crystallization processes of the ABW zeolite. Fig. 5 shows the IR spectra recorded from samples hydrothermally treated at different times. Only four IR bands were detected in the sample heated for $10 \mathrm{~min}$ : at $1113,1019,802$ and $472 \mathrm{~cm}^{-1}$ which are typical for amorphous aluminosilicates (Fig. 5a) [5]. The IR spectrum of the sample heated for 17 min contain bands at 1009 and $1128 \mathrm{~cm}^{-1}$, which were assigned to the internal vibrations of $\mathrm{Si}-\mathrm{O}-\mathrm{T}(\mathrm{T}=\mathrm{Si}, \mathrm{Al})$ 
asymmetric stretching modes (Fig. 5b) [17]. On the other hand, another IR band at $1053 \mathrm{~cm}^{-1}$ assigned to the $\mathrm{Si}-\mathrm{O}-\mathrm{T}$ symmetric stretching vibration mode appeared [46]. The intensity of these bands increased in the samples subjected to longer crystallization and also a peak shifting was observed indicating the change of the chemical composition of the sample, i.e., increased of $\mathrm{Al}$ content (Fig. 5b-d). Additionally, several weak bands at 530, 547 and 604 and $666 \mathrm{~cm}^{-1}$, which are characteristics of double zigzag chains (dzc) in the Cs-ABW zeolite, started to appear in the sample treated for 30 min [47]. This double zigzag chains are composed of 4-rings and when they are connected, an 8-ring channels are formed [48]. Thus, the presence of these four IR bands indicated that the crystalline Cs-ABW zeolite is formed. A weak band at $448 \mathrm{~cm}^{-1}$ corresponding to the $\mathrm{TO}_{4}$ bending vibration was also detected, and it slightly shifted to $440 \mathrm{~cm}^{-}$ ${ }^{1}$ for the sample treated for120 min (Fig. 5b) [46]. All of these IR characteristic bands became more pronounced upon increasing crystallization time and no change in the IR spectrum was observed after 120 min of crystallization showing that fully crystalline Cs-ABW had been obtained (Fig. 5c,d).

The chemical composition of the solid products was determined using ICP-OES spectroscopy. In general, the Si content decreased while the $\mathrm{Al}$ and $\mathrm{Cs}$ contents increased with increasing the crystallinity of the samples under prolonged heating time (Table 2). At 10 min, the $\mathrm{Si} / \mathrm{Al}$ ratio was 11.28 indicating that self-polymerization among silicate species is more favorable than the aluminate species [49]. Furthermore, low Cs/Al ratio (0.35) was also measured due to the presence of merely amorphous $\mathrm{Al}$ anionic species unable electrostatically to bind with the $\mathrm{Cs}^{+}$cations [50]. At $17 \mathrm{~min}$, the $\mathrm{Si} / \mathrm{Al}$ ratio decreased drastically to 1.87 while the $\mathrm{Cs} / \mathrm{Al}$ ratio increased to 0.71 suggesting that structure rearrangement and mass transformation of the amorphous into crystalline material are proceeding. The Si/Al ratio finally reached almost unity when fully crystalline Cs-ABW solids were obtained. Thus, the high alumina Cs-ABW zeolite nanocrystals had been obtained. The elemental composition of 
the ABW nanocrystals is similar to the one reported by Gatta et al. [39]. According to Gatta et al., the $\mathrm{Cs}^{+}$cations are located off-center in the $8 \mathrm{MR}$-channels as extra-framework species where staggering of $\mathrm{Cs}^{+}$cations can be well seen in projection onto the plane of the 6-MRs of tetrahedra.

The ${ }^{27} \mathrm{Al}$ solid state MAS NMR spectra of all samples were also recorded. The spectra contain a resonance peak at $56 \mathrm{ppm}$ which is corresponding to Al species in tetrahedral coordination (Fig. 6). Since this is the coordination state of Al in both amorphous and zeolite phases, this result did not provide distinguished information about the samples with different degree of crystallinity. The peak centred at $55.4 \mathrm{ppm}$ became more narrower in the sample after 17 min heating, indicating homogeneous surrounding of the $\mathrm{Al}$ species and high symmetry (Fig. 6b). On the other hand, the ${ }^{28} \mathrm{Si}$ MAS NMR spectra show more information concerning the environment of the $\mathrm{Si}$ species in amorphous, semi-crystalline and crystalline samples. For the solid obtained after $10 \mathrm{~min}$ of heating, an intense and broad signal centred at $-111.2 \mathrm{ppm}$ was detected indicating the presence of unreacted silica in the form of $\mathrm{Si}(\mathrm{OSi})_{4}$ (Fig. 7a). Two smaller contributions were also observed at $-100.4 \mathrm{ppm}$ and $-86.2 \mathrm{ppm}$. The first band could be attributed to the $\mathrm{Q}_{4}$ groups $\left(\mathrm{Si}(\mathrm{OSi})_{3}(\mathrm{OAl})\right)$ and/or $\mathrm{Q}_{3}$ groups $\left(\mathrm{Si}(\mathrm{OSi})_{3}(\mathrm{OH})\right)$, while the second band was attributed to $\mathrm{Q}_{2}$ groups $\left(\mathrm{Si}^{-}(\mathrm{OSi})(\mathrm{OAl})_{3}\right)$ and/or $\mathrm{Q}_{3}$ groups $\left(\mathrm{Si}(\mathrm{OAl})_{2}(\mathrm{OSi})(\mathrm{OH})\right)[51]$. Increasing the heating time to $17 \mathrm{~min}$ and above evidenced the disappearance of the resonance at $-111.2 \mathrm{ppm}$ and the appearance of a well-defined resonance centered at ca. $-94 \mathrm{ppm}\left(\right.$ Fig.7b-d) which was attributed to $\mathrm{Q}_{4}$ groups. This sharp peak corresponded to the unique Si crystallographic site of ABW framework. Another peak ca. $-88 \mathrm{ppm}$ was also observed for these three samples which was attributed to $\mathrm{Q}_{3}$ groups $\left(\mathrm{Si}(\mathrm{OAl})_{2}(\mathrm{OSi})(\mathrm{OH})\right)$ thanks to ${ }^{1} \mathrm{H}-{ }^{29} \mathrm{Si}$ CPMAS experiments (results not shown). The intensity of this peak seemed to decrease while increasing the 
heating time of the samples indicating a higher degree of crystallinity for the sample heated for 120 min compared to the other samples; these results are consistent with the XRD data.

\section{Conclusions}

In summary, the synthesis of nanosized $\mathrm{ABW}$ - type zeolite containing $\mathrm{Cs}^{+}$extra framework cations in hydrogel free of organic template is presented. From an environmental point of view, this synthesis is beneficial as the ABW nanosized zeolite can be prepared under mild pressure and temperature without using harmful organic template. The nanocrystalline Cs-ABW zeolite can be easily obtained within 120 min hydrothermal treatment at $180{ }^{\circ} \mathrm{C}$ without using any organic template and the synthesis condition is very mild as compared to that reported in previous works. The formation of nanosized Cs-ABW zeolite is initiated by oligomerization of alumina and silica units in precursor solution, followed by polymerization to form amorphous entities before nuclei formation, crystallization and crystal growth take place under prolonged crystallization time. The resulting nanocrystals have an average diameter of $32 \mathrm{~nm}$ and narrow particle size distribution. The work presented can be beneficial for catalytic and selective sorption applications since the zeolite nanocrystals contain high basicity, small pores and have high solid yield (>80\%).

\section{Acknowledgments}

The financial support from RUI (1001/PKIMIA/8011012), SATU Joint Research Scheme (RU018O-2016) is acknowledged. 


\section{References}

[1] S.M. Al-Jubouri, S.M. Holmes, Chem. Eng. J. 308 (2017) 476-491.

[2] G. Majano, E.-P. Ng, L. Lakiss, S. Mintova, Green Chem. 13 (2011) 2435-2440.

[3] B. Liu, Z. Chen, J. Huang, H. Chen, Y. Fang, Micropor. Mesopor. Mater. 273 (2019) 235-242.

[4] M. Rahimi, E.-P. Ng, K. Bakhtiari, M. Vinciguerra, H.A. Ahmad, H. Awala, S. Mintova, M. Daghighi, F.B. Rostami, M. de Vries, M.M. Motazacker, M.P. Peppelenbosch, M. Mahmoudi, F. Rezaee, Sci. Rep. 5 (2015) 17259.

[5] S.-F. Wong, K. Deekomwong, J. Wittayakun, T.C. Ling, O. Muraza, F. Adam, E.-P. Ng, Mater. Chem. Phys. 196 (2017) 295-301.

[6] G. Huang, P. Ji, H. Xu, J.-G. Jiang, P. Wu, Micropor. Mesopor. Mater. 248 (2017) 3039.

[7] B.A. Holmberg, X. Wang, Y. Yan, J. Membrane Sci. 320 (2008) 86-92.

[8] E.-P. Ng, D.T.L. Ng, H. Awala, K.-L. Wong, S. Mintova, Mater. Lett. 132 (2014) 126129.

[9] S. Mintova, N.H. Olson, V. Valtchev, T. Bein, Science 283 (1999) 958-960.

[10] W. Song, V.H. Grassian, S.C. Larsen, Chem. Commun. (2005) 2951-2953.

[11] L. Shi, N. Li, L. Wang, R. Liu, Y. Li, Micropor. Mesopor. Mater. 258 (2018) 178-188.

[12] Y. Kamimura, S. Tanahashi, K. Itabashi, A. Sugawara, T. Wakihara, A. Shimojima, T. Okubo, J. Phys. Chem. C 115 (2011) 744-750. 
[13] D.Y. Khoo, W.-M. Kok, R.R. Mukti, S. Mintova, E.-P. Ng, Solid State Sci. 25 (2013) 63-69.

[14] T. Wakihara, R. Ichikawa, J. Tatami, A. Endo, K. Yoshida, Y. Sasaki, K. Komeya, T. Meguro, Cryst. Growth Des. 11 (2011) 955-958.

[15] H. Yamada, T. Iida, Z. Liu, Y. Naraki, K. Ohara, S. Kohara, T. Okubo, T. Wakihara, Cryst. Growth Des. 16 (2016) 3389-3394.

[16] H. Wang, B.A. Holmberg, Y. Yan, J. Am. Chem. Soc. 125 (2003) 9928-9929.

[17] E.-P. Ng, G.K. Lim, G.-L. Khoo, K.-H. Tan, B.S. Ooi, F. Adam, T.C. Ling, K.-L. Wong, Mater. Chem. Phys. 155 (2015) 30-35.

[18] Y. Wang, Q. Wu, X. Meng, F.-S. Xiao, Engineering 3 (2017) 567-574.

[19] Y. Kamimura, W. Chailittisilp, K. Itabashi, A. Shimojima, T. Okubo, Chem. Asian J. 5 (2010) 2182-2191.

[20] E.-P. Ng, H. Awala, J.-P. Ghoy, A. Vicente, T.C. Ling, Y.H. Ng, S. Mintova, F. Adam, Mater. Chem. Phys. 159 (2015) 38-45.

[21] H. Awala, J.P. Gilson, R. Retoux, P. Boullay, J.M. Goupil, V. Valtchev, S. Mintova, Nat. Mater. 14 (2015) 447-451.

[22] V.P. Valtchev, K.N. Bozhilov, J. Phys. Chem. B 108 (2004) 15587-15598.

[23] J. Kecht, B. Mihailova, K. Karaghiosoff, S. Mintova, T. Bein, Langmuir 20 (2004) $5271-5276$.

[24] V.P. Valtchev, L. Tosheva, K.N. Bozhilov, Langmuir 21 (2005) 10724-10729. 
[25] M. Tsapatsis, T. Okubo, M. Lovallo, M.E. Davis, Mat. Res. Soc. Symp. Proc. 371 (1995) 21-26.

[26] Y. Liu, M. Sun, C.M. Lew, J. Wang, Y. Yan, Adv. Funct. Mater. 18 (2008) 1732-1738.

[27] Y.-W. Cheong, K.-L. Wong, T.C. Ling, E.-P. Ng, Mater. Express 8 (2018) 1-6.

[28] K. Jiao, X. Xu, Z. Lv, J. Song, M. He, H. Gies, Micropor. Mesopor. Mater. 225 (2016) 98-104.

[29] T. Kurniawan, O. Muraza, K. Miyake, A.S. Hakeem, Y. Hirota, A.M. Al-Amer, N. Nishiyama, Ind. Eng. Chem. Res. 56 (2017) 4258-4266.

[30] W. Fan, K. Morozumi, R. Kimura, T. Yokoi, T. Okubo, Langmuir 24 (2008) 6952-6958.

[31] E.-P. Ng, L. Delmotte, S. Mintova, Green Chem. 10 (2008) 1043-1048.

[32] E.-P. Ng, K.-L. Wong, D.T.-L. Ng, H. Awala, R.R. Mukti, F. Adam, S. Mintova, Mater. Chem. Phys. 188 (2017) 49-57.

[33] G. Majano, K. Raltchev, A. Vicente, S. Mintova, Nanoscale 7 (2015) 5787-5793.

[34] X. Chen, D. Xi, Q. Sun, N. Wang, Z. Dai, D. Fan, V. Valtchev, J. Yu, Micropor. Mesopor. Mater. 234 (2016) 401-408.

[35] R.M. Barrer, E.A.D. White, J. Chem. Soc. (1951) 1267.

[36] IZA-SC Database of Zeolite Structures. http://www.iza-structure.org/ databases/.

[37] P. Norby, A. Nørlund Christensen, I. G. Krogh Andersen, Acta Chem. Scand. A40 (1986) 500 .

[38] R. Klaska, O. Jarchow, Naturwiss. 60 (1973) 299.; R. Klaska, O. Jarchow, Z. Kristallogr. 142 (1975) 225-238. 
[39] G.D. Gatta, N. Rotiroti, P.F. Zanazz, M. Rieder, M. Drabek, Z. Weiss, R. Klaska, Am. Mineral. 93 (2008) 988-995.

[40] G.D. Gatta, M. Merlini, P. Lotti, A. Lausi, M. Rieder, Micropor. Mesopor. Mater. 163 (2012) 147-152.

[41] D. Massiot, F. Fayon, M. Capron, I. King, S. Le Calvé, B. Alonso, J.-L. Durand, B. Bujoli, Z. Gan, G. Hoatson, Magn. Reson. Chem. 40 (2002) 70-76.

[42] H. Maghsoodloorad, S.M. Mirfendereski, T. Mohammadi, A. Pak, Clay Clay Miner 59 (2011) 328-335.

[43] J.-L. Guth, H. Kessler, in: J. Weitkamp, L. Puppe (Eds.), Catalysis and Zeolites: Fundamentals and Applications, Springer-Verlag, Berlin, 1999, pp. 20-21.

[44] HG. Liu, Q. Shi, L. Liu, H. Xu, J. Li and J. Dong, Stud. Surf. Sci. Catal. 174A (2008) 185-188.

[45] K. Spektor, A. Fischer, U. Haussermann, Inorg. Chem. 55 (2016) 8048-8058.

[46] S.-F. Wong, H. Awala, A. Vincente, R. Retoux, T.C. Ling, S. Mintova, R.R. Mukti, E.P. Ng, Micropor. Mesopor. Mater. 249 (2017) 105-110.

[47] P. Guo, Structure Determination and Prediction of Zeolites, PhD thesis, Stockholm University, 2016, 73.

[48] Ch. Baerlocher, W.M. Meier, D.H. Olson, Atlas of Zeolite Framework Types, Elsevier, Amsterdam, 2001, pp. 26-27.

[49] L Itani, Y Liu, W Zhang, KN Bozhilov, L Delmotte, V Valtchev, J. Am. Chem. Soc. 131 (2009) 10127-10139.

[50] V.P. Valtchev, K.N. Bozhilov, J. Am. Chem. Soc. 127 (2005) 16171-16177.

[51] G. Engelhardt, Stud. Surf. Sci. Catal. 137 (2001) 387-418. 


\section{Graphical abstract}

- Organic template free

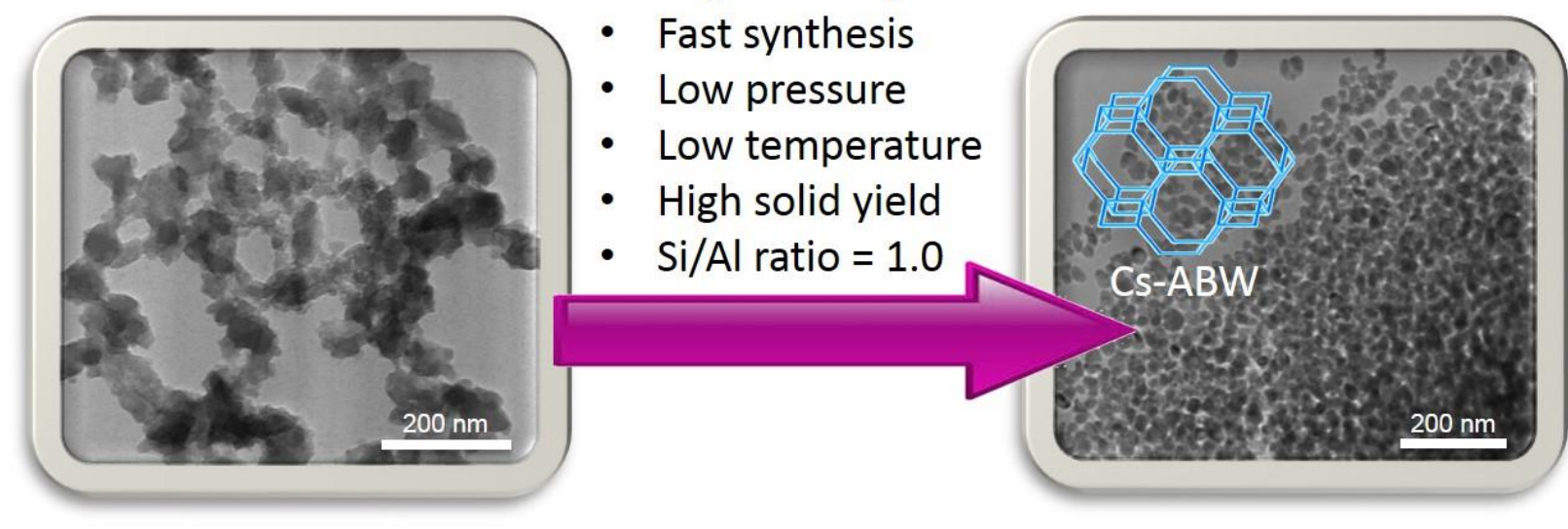

\section{Research highlights}

- Cs-ABW zeolite is prepared under low temperature $\left(180^{\circ} \mathrm{C}\right)$ and pressure $(22 \mathrm{bar})$.

- The synthesis condition is much safer and faster than that of previous works.

- The nucleation and crystallization of nanozeolites in template-free hydrogel are studied.

- Fully crystalline Cs-ABW nanocrystals are formed after $120 \mathrm{~min}$.

- The crystals (ca. $32 \mathrm{~nm}, \mathrm{Si} / \mathrm{Al}=1.0$ ) have grain shape morphology.

- High solid yield offering large-scale production of highly basic zeolite nanoparticles. 


\section{Figure captions}

Fig. 1. Yield of solids recovered after different time intervals of hydrothermal synthesis.

Fig. 2. XRD patterns of samples after heating for (a) $10 \mathrm{~min}$, (b) $17 \mathrm{~min}$, (c) $30 \mathrm{~min}$, (d) $60 \mathrm{~min}$ and (e) 120 min. The theoretical XRD pattern reported in ref. [39] is shown in (f).

Fig. 3. Degree of crystallinity of samples after heating for various times.

Fig. 4. TEM images of samples collected after hydrothermal treatment for (a, b) $10 \mathrm{~min},(\mathrm{c}, \mathrm{d})$ $17 \mathrm{~min},(\mathrm{e}, \mathrm{f}) 30 \mathrm{~min}$ and $(\mathrm{g}, \mathrm{h}) 120 \mathrm{~min}$.

Fig. 5. FTIR spectra of the solid after hydrothermal treatment for (a) $10 \mathrm{~min}$, (b) $17 \mathrm{~min}$, (c) $30 \mathrm{~min}$ and (d) $120 \mathrm{~min}$.

Fig. 6. ${ }^{27} \mathrm{Al}$ solid state MAS NMR spectra of the solid after hydrothermal treatment for (a) 10 min, (b) $17 \mathrm{~min}$, (c) $30 \mathrm{~min}$ and (d) $120 \mathrm{~min}$.

Fig. 7. ${ }^{28} \mathrm{Si} \mathrm{MAS} \mathrm{+} \mathrm{DEC} \mathrm{NMR} \mathrm{spectra} \mathrm{of} \mathrm{the} \mathrm{solid} \mathrm{samples} \mathrm{after} \mathrm{hydrothermal} \mathrm{treatment} \mathrm{for}$ (a) $10 \mathrm{~min}$, (b) $17 \mathrm{~min}$, (c) $30 \mathrm{~min}$ and (d) $120 \mathrm{~min}$. 


\section{Figures}

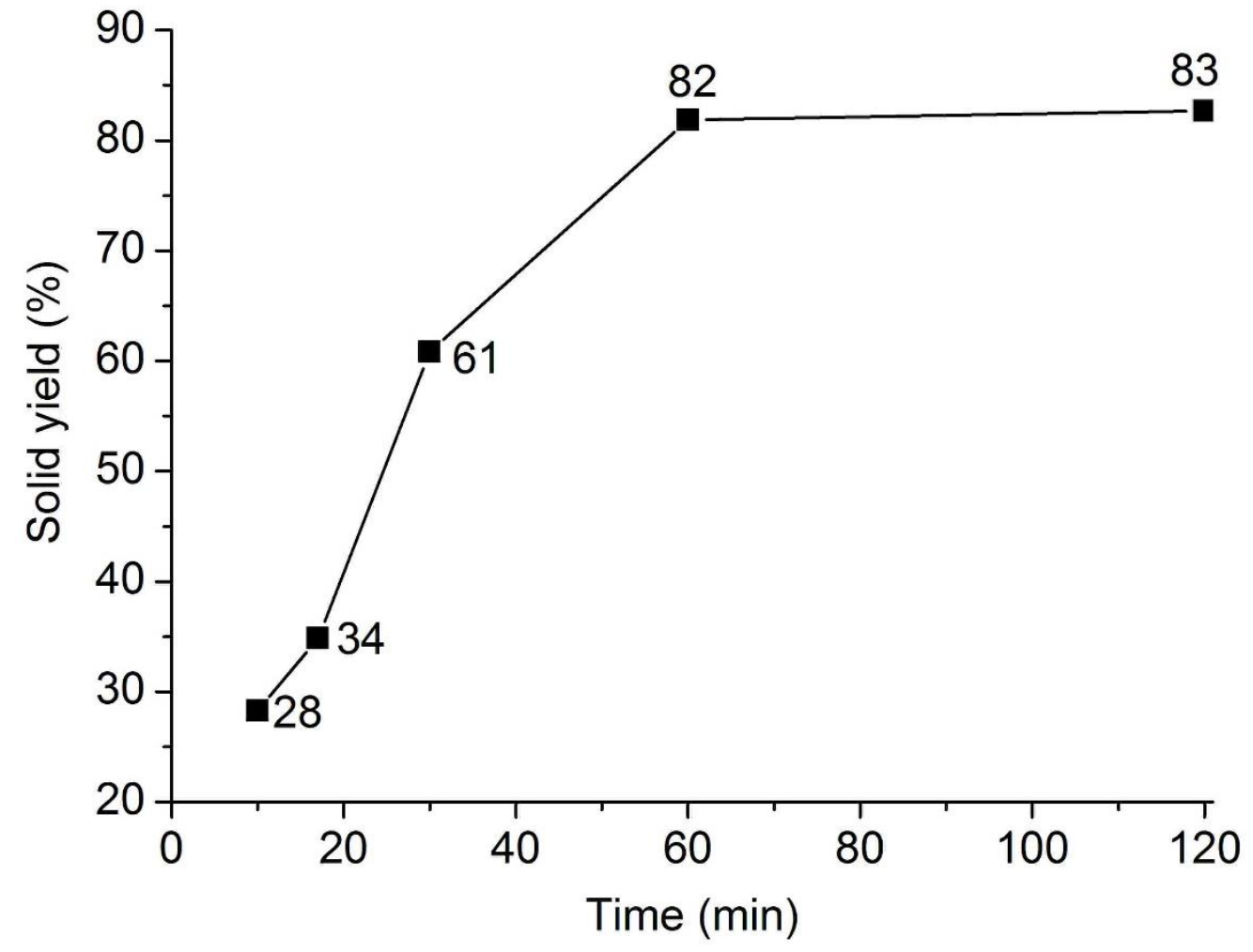

Fig. 1. 


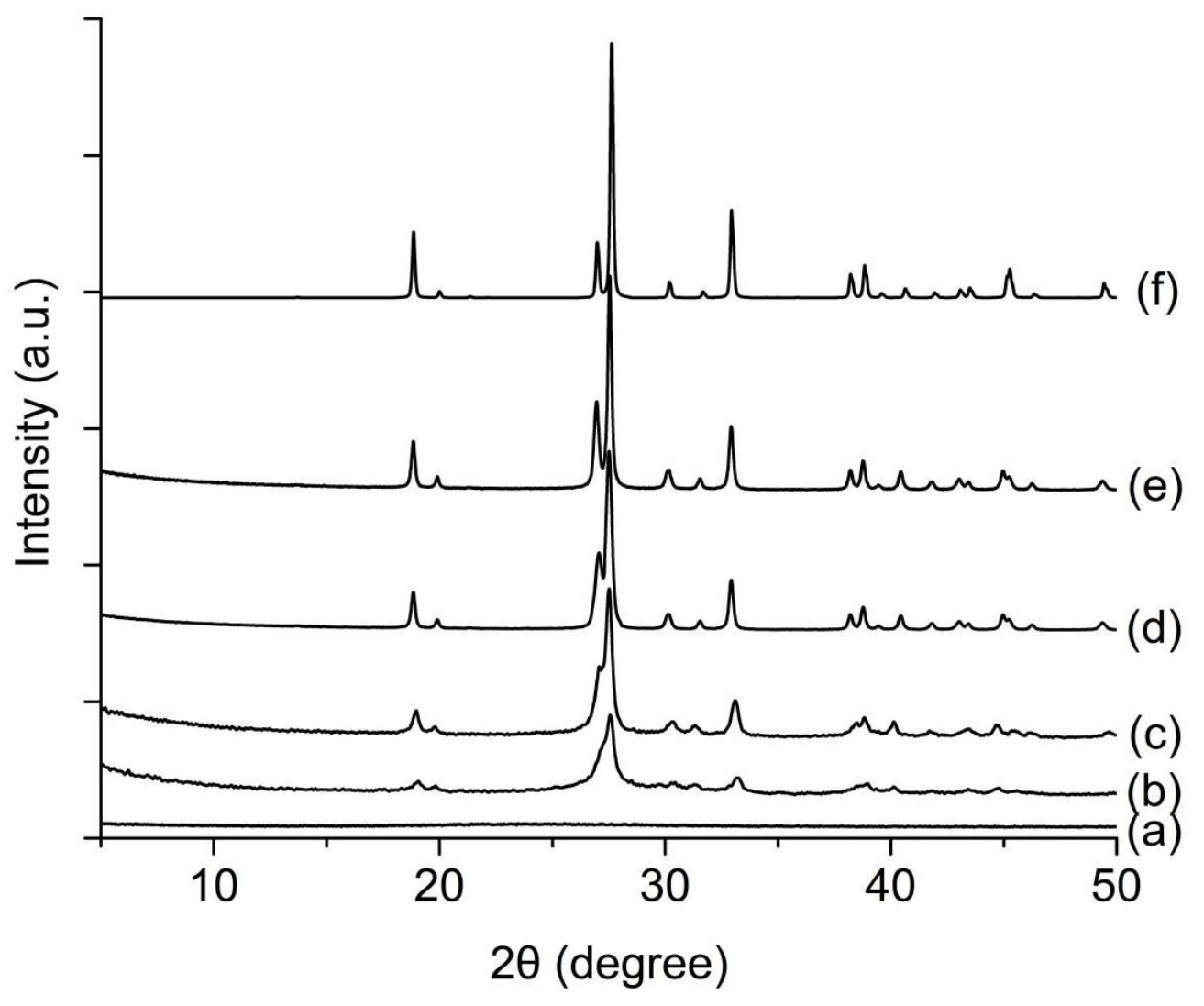

Fig. 2. 


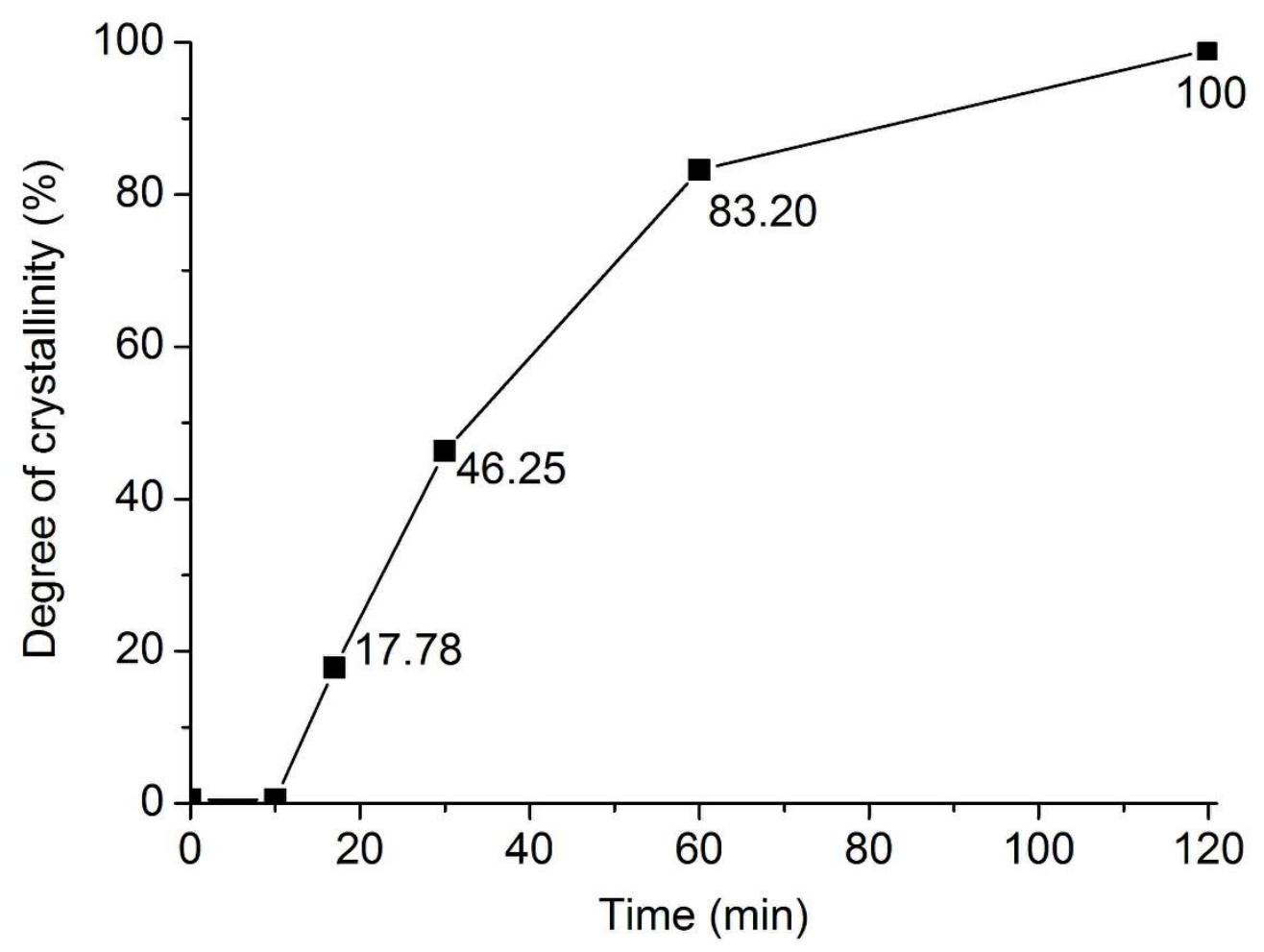

Fig. 3. 


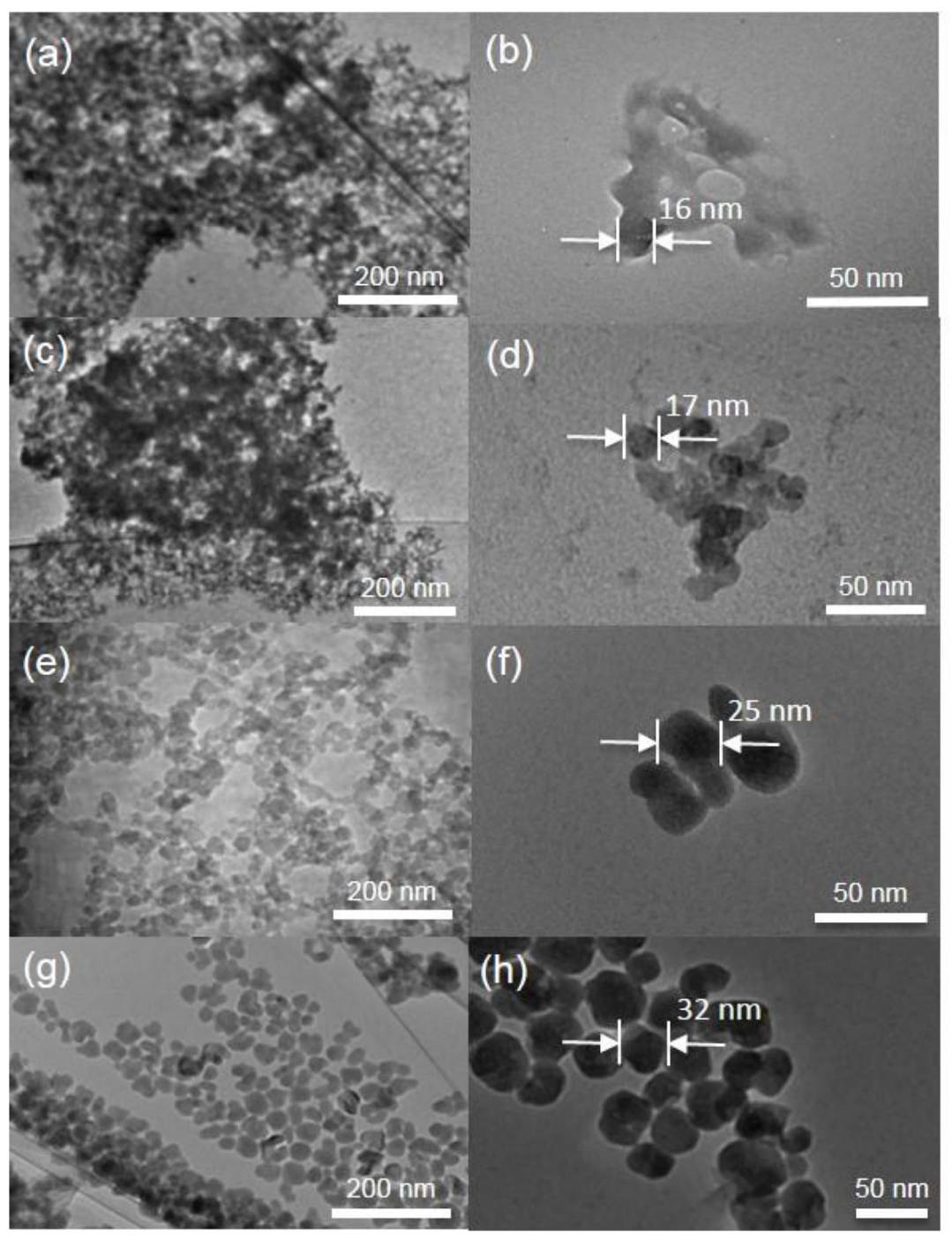

Fig. 4. 


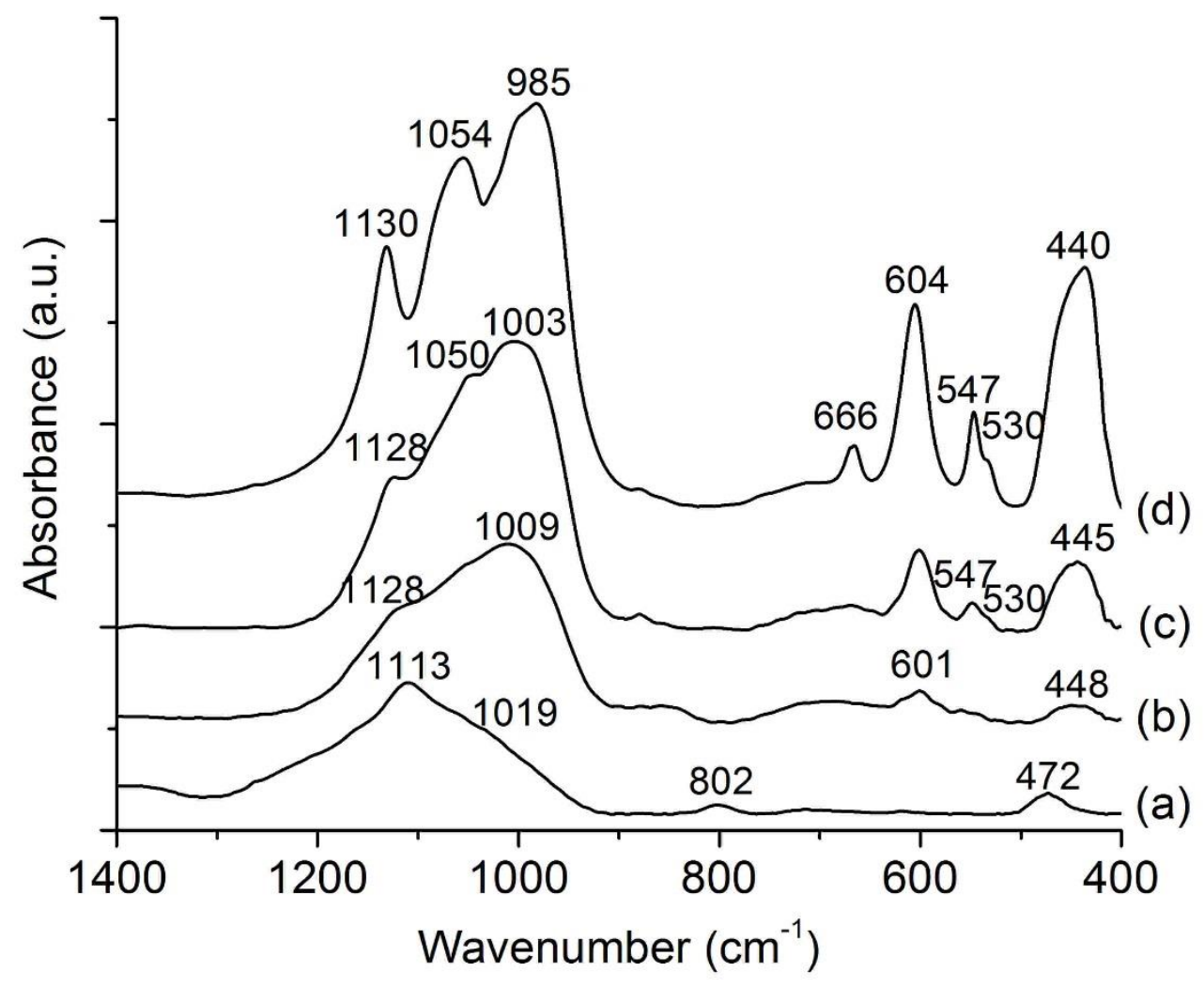

Fig. 5. 


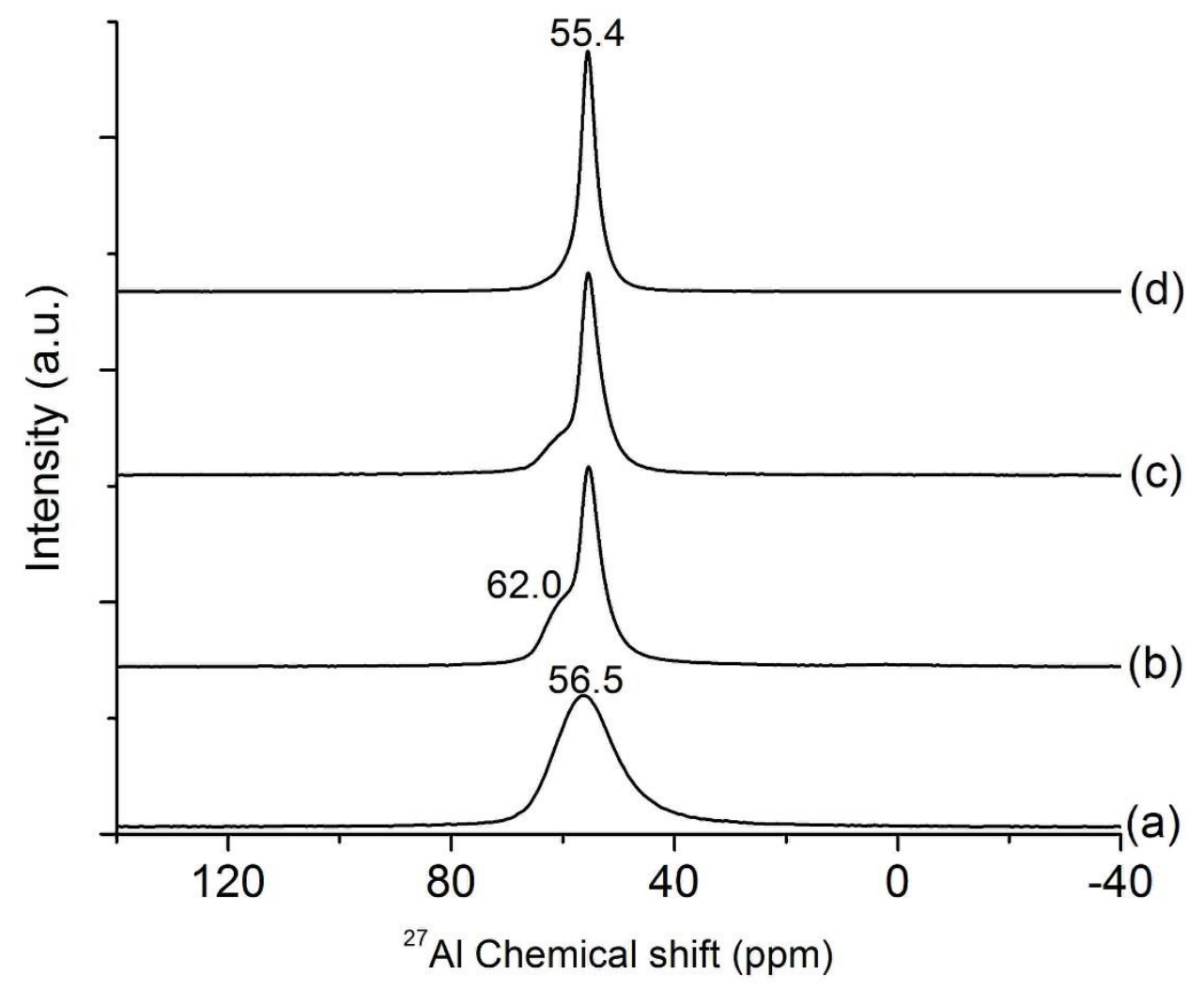

Fig. 6. 


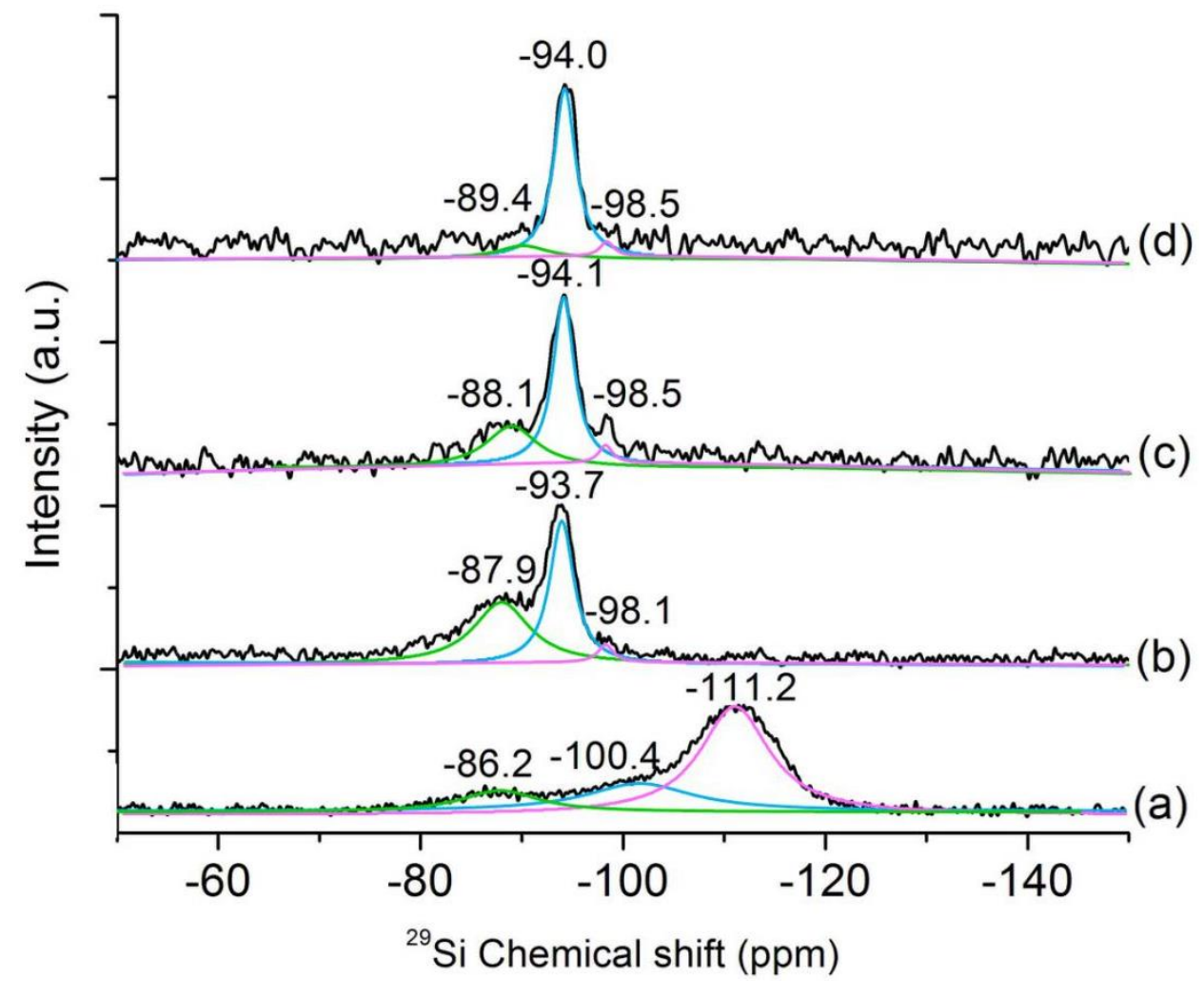

Fig. 7. 


\section{$\underline{\text { Tables }}$}

Table 1. Synthesis conditions and characteristics of solid products obtained from hydrothermal syntheses.

\begin{tabular}{|c|c|c|c|c|c|c|c|c|}
\hline \multirow{2}{*}{$\begin{array}{c}\text { Variable } \\
\text { parameters }\end{array}$} & \multirow{2}{*}{ Entry } & \multicolumn{4}{|c|}{ Gel molar composition } & \multirow{2}{*}{$\begin{array}{c}\mathbf{T} \\
\left({ }^{\circ} \mathbf{C}\right)\end{array}$} & \multirow{2}{*}{$\begin{array}{c}\mathbf{t} \\
(\mathbf{m i n})\end{array}$} & \multirow{2}{*}{ Products $^{\mathrm{a}}$} \\
\hline & & $\mathrm{SiO}_{2}$ & $\mathrm{Al}_{2} \mathrm{O}_{3}$ & $\mathrm{Cs}_{2} \mathrm{O}$ & $\mathrm{H}_{2} \mathrm{O}$ & & & \\
\hline \multirow{3}{*}{$\mathrm{Cs}_{2} \mathrm{O}$} & 1 & \multirow{3}{*}{4} & \multirow{3}{*}{1} & 8 & \multirow{3}{*}{164} & \multirow{3}{*}{180} & \multirow{3}{*}{80} & Am. \\
\hline & 2 & & & 12 & & & & $\mathrm{ABW}(41)$ \\
\hline & 3 & & & 16 & & & & $\mathrm{ABW}(26)$ \\
\hline \multirow{3}{*}{$\mathrm{H}_{2} \mathrm{O}$} & 4 & \multirow{3}{*}{4} & \multirow{3}{*}{1} & \multirow{3}{*}{16} & 124 & \multirow{3}{*}{180} & \multirow{3}{*}{80} & $\mathrm{ABW}(19)$ \\
\hline & 3 & & & & 164 & & & $\mathrm{ABW}(26)$ \\
\hline & 5 & & & & 204 & & & $\mathrm{ABW}(44)$ \\
\hline \multirow{3}{*}{$\begin{array}{l}\mathrm{SiO}_{2} / \mathrm{Al}_{2} \mathrm{O}_{3} \\
\text { ratio }\end{array}$} & 6 & 2 & \multirow{3}{*}{1} & \multirow{3}{*}{16} & \multirow{3}{*}{164} & \multirow{3}{*}{180} & \multirow{3}{*}{80} & ABW (34) \\
\hline & 3 & 4 & & & & & & ABW (26) \\
\hline & 7 & 6 & & & & & & Am. \\
\hline \multirow{3}{*}{$\begin{array}{c}\text { Metal } \\
\text { hydroxide }\end{array}$} & 9 & \multirow{3}{*}{4} & \multirow{3}{*}{1} & $\begin{array}{c}16 \\
\mathrm{Na}_{2} \mathrm{O}\end{array}$ & \multirow{3}{*}{164} & \multirow{3}{*}{180} & \multirow{3}{*}{80} & CAN (57) \\
\hline & 10 & & & $\begin{array}{c}16 \\
\mathrm{~K}_{2} \mathrm{O} \\
\end{array}$ & & & & LTJ (94) \\
\hline & 3 & & & $\begin{array}{c}16 \\
\mathrm{Cs}_{2} \mathrm{O} \\
\end{array}$ & & & & $\mathrm{ABW}(26)$ \\
\hline \multirow{3}{*}{ Temperature } & 11 & \multirow{3}{*}{4} & \multirow{3}{*}{1} & \multirow{3}{*}{16} & & 140 & & Am. \\
\hline & 12 & & & & 164 & 160 & 80 & Am. > ABW (16) \\
\hline & 3 & & & & & 180 & & $\mathrm{ABW}(26)$ \\
\hline & 13 & & & & & & 10 & Am. \\
\hline & 14 & & & & & & 17 & Am. $\gg$ ABW (15) \\
\hline Time & 15 & 4 & 1 & 16 & 164 & 180 & 30 & Am. > ABW (21) \\
\hline & 16 & & & & & & 60 & $\mathrm{ABW}(25)>\mathrm{Am}$ \\
\hline & 17 & & & & & & 120 & $\mathrm{ABW}(28)$ \\
\hline
\end{tabular}


${ }^{\mathrm{a}} \mathrm{Am} .=$ Amorphous phase; the crystallite size $(\mathrm{nm})$ estimated using Scherrer equation is shown in the last column in brackets.

Table 2. Chemical elemental analysis of the solid products obtained after various heating times.

\begin{tabular}{|c|c|c|c|c|c|c|c|c|}
\hline \multirow{2}{*}{ Samples } & \multicolumn{2}{|c|}{$\mathrm{Si}$} & \multicolumn{2}{|c|}{$\mathrm{Al}$} & \multicolumn{2}{|c|}{ Cs } & \multirow{2}{*}{$\begin{array}{l}\mathrm{Si} / \mathrm{Al} \\
\text { ratio }\end{array}$} & \multirow{2}{*}{$\begin{array}{c}\mathrm{Cs} / \mathrm{Al} \\
\text { ratio }\end{array}$} \\
\hline & $\mathrm{mg} / \mathrm{L}$ & $\mathrm{mmol} / \mathrm{L}$ & $\mathrm{mg} / \mathrm{L}$ & $\mathrm{mmol} / \mathrm{L}$ & $\mathrm{mg} / \mathrm{L}$ & $\mathrm{mmol} / \mathrm{L}$ & & \\
\hline $10 \mathrm{~min}$ & 318.9 & 11.39 & 27.3 & 1.01 & 46.1 & 0.35 & 11.28 & 0.35 \\
\hline $17 \mathrm{~min}$ & 165.0 & 5.89 & 83.9 & 3.10 & 303.8 & 2.29 & 1.90 & 0.74 \\
\hline $30 \mathrm{~min}$ & 110.9 & 3.96 & 85.0 & 3.15 & 402.8 & 3.03 & 1.25 & 0.95 \\
\hline $120 \mathrm{~min}$ & 90.1 & 3.22 & 85.1 & 3.15 & 441.8 & 3.32 & 1.02 & 1.05 \\
\hline
\end{tabular}

